\title{
Hohe Abtragsraten in kürzerer Zeit
}

\author{
Ein hoher Abtrag beim Schleifen spart Zeit und Kosten. \\ Mit speziell angepassten Schleifplättchen sind deutlich \\ effizientere Schleifprozesse möglich. Auch die thermische \\ Belastung von Werkstücken wird gezielt gesenkt.
}

\section{Horst Honig}

Vielfältige Gründe machen einen Schleifprozess an Werkstücken erforderlich: spezielle Anforderungen an die Oberflächenstruktur, die Entfernung von Verunreinigungen, Anstrichen oder Rost, das Entgraten oder auch das Schleifen in eine bestimmte Form. Aber Schleifen kostet auch Zeit und damit Geld. Entscheidend für einen wirtschaftlichen Schleifprozess sind hohe Abtragsraten und damit effizientere Prozesse. Diese Abtragsraten erzielt das Schleifmittel Cubitron II von 3M durch die Mikroreplikation.

Mikroreplikation in der Schleiftechnik bedeutet die milliardenfache exakte Fertigung einer winzig kleinen definierten Form eines Schleifkorns, das - auf ein Trägermaterial aufgebracht - einem Schleifmittel besondere mechanische Eigenschaften verleiht. Ursprünglich entwickelt wurde die Technik in den sechziger Jahren zur Herstellung flacher Kunststofflinsen für Tageslichtprojektoren. Im Laufe der Jahre zeigten sich vermehrt neue Anwendungsfelder für die innovative Technologie. Und eine davon ist das Schleifen mit hochpräzisem Schleifkorn.

\section{Präzise Formen statt zufälliger Brechung}

Für die Herstellung von Keramik-Schleifkörnern, die dann in Schleifscheiben und -bändern Verwendung finden, wird ein normalerweise geleeförmiges Rohmaterial gesintert, das heißt gebacken, nicht geschmolzen. Das dadurch entstehende sehr harte und sehr zähe Schleifmittel wird anschließend auf die gewünsch- te Korngröße gebrochen und auf das Trägermaterial aufgebracht. Durch diese Brechung hat jedes Schleifkorn eine andere Form und damit auch willkürliche Bruch-Eigenschaften.

Die Mikroreplikation ermöglicht die Herstellung exakt gleicher Schleifkörner. Dazu wird vor dem Sintern das Gelee aus einem Grundmaterial in kleine Formen gefüllt. Durch das Sintern entstehen so absolut identische Schleifplättchen in Form von gleichseitigen Dreiecken. Diese werden bei Fiberscheiben, Fächerscheiben und Schleifbändern auf das Trägermaterial aufgebracht. Durch elektrostatische Aufladung sind alle Plättchen senkrecht ausgerichtet.

\section{Reduzierte thermische Belastung}

Das Ergebnis dieses Prozesses ist ein signifikant höherer und schnellerer Abtrag im Vergleich zu herkömmlichen Schleifmitteln. Durch die Mikroreplikation ist es möglich, dass bei jedem Schleifkorn immer zwei Spankeile entlang einer präzisen Kornflanke durch das Material schneiden, und zwar so lange, bis das freie Schleifkorn verbraucht ist. Durch die neuartige Schnittgeometrie gleitet das Schleifkorn durch den Werkstoff. Das sonst beim Schleifen bekannte Pflügen und Verdrängen von Metall wird vermieden. Mit dem gleichen Energieaufwand wird ein wesentlich höherer Abtrag in kürzerer Zeit erzielt.

Ein zusätzlicher Nebeneffekt liegt in der reduzierten Reibung. In Verbindung mit dem beschleunigten Schleifprozess verringert sich auch die thermische Belas-

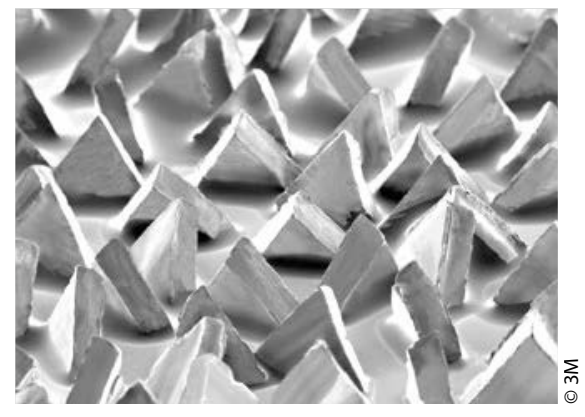

Speziell angepasste Schleifplättchen schneiden mit zwei scharfen Kanten durch das Werkstück.

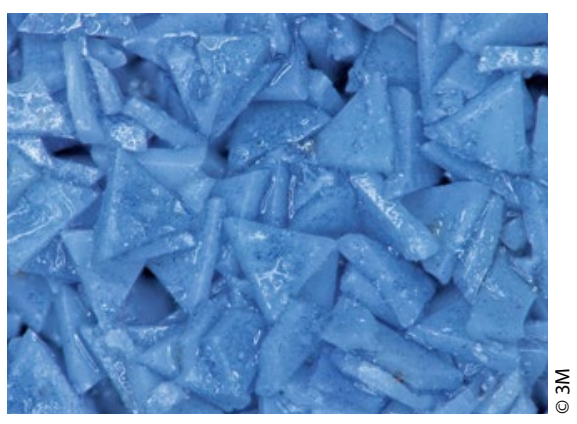

Durch Mikroreplikation entstehen exakt gleiche Schleifplättchen.

tung des Werkstücks. Restwärme wird im Span mit Cubitron II Schleifmitteln direkt aus dem Werkstück abgeführt, so dass Anlauffarben und Gefügeveränderungen sehr spät, wenn überhaupt auftreten.

\section{Weitere Einflüsse auf den Schleifprozess}

Neben der Art und Form des Schleifkorns gibt es weitere Faktoren, die Dauer und Ergebnis eines Schleifprozesses beeinflussen, so zum Beispiel die Anzahl der Schleifkörner im Schleifmedium. Je weniger Schleifkörner, desto höher der Abtrag, da der Druck auf jedes einzelne Schleifkorn steigt. Das grobe Schruppen wird nochmals beschleunigt und geht einher mit einer etwas gröberen aber gleichmäßigen Oberfläche im Grobkornbereich. Mehr Schleifkörner im feineren Körnungsbereich bedeuten feinere Oberflächen. Hier ist hoher Spanabtrag unerwünscht, um eine dauerhafte Oberflächenverbesserung zu erzielen. //

\section{Der Autor}

Horst Honig, Senior Sales Specialist $3 \mathrm{M}$ Deutschland $\mathrm{GmbH}$, Neuss schleifen.de@3M.com

Tel. 02131142710

www.3m.de/schleifen 